\title{
The Briard dog: a new animal model of congenital stationary night blindness
}

\author{
KRISTINA NARFSTRÖM, ANDERS WRIGSTAD, AND SVEN ERIK G NILSSON \\ From the Department of Ophthalmology, University of Linköping, S-581 85 Linköping, and Department of \\ Surgery and Medicine, Faculty of Veterinary Medicine, Swedish University of Agricultural Sciences, S-750 07 \\ Uppsala, Sweden
}

SUMMARY Congenital stationary night blindness (CSNB), apparently inherited in an autosomal recessive manner, was observed in a litter of Briard dogs in Sweden. Of nine litter mates five had nyctalopia. The results of different clinical tests, including electroretinography (ERG), were compared with the results found in four human cases of CSNB, three of which were most probably associated with autosomal recessive inheritance and one with X-linked inheritance. The congenital and stationary nature of the disease, ophthalmoscopically normal appearing fundi, and recordable but reduced photopic flicker responses were some of the similarities found between canine and human cases. The single-flash ERG response was abnormal in the humans as well as in the affected Briards. However, the human cases showed a 'negative' ERG, whereas in the Briards both the a and $b$ waves were extremely reduced and present only at a photopic level. Cases similar to these Briards have been described also in man, where rhodopsin concentration and regeneration were found to be normal, suggesting a disturbed transduction mechanism. It thus appears that the Briard dog may become a valuable model of human CSNB.

A group of retinal disorders in man known collectively as congenital stationary night blindness (CSNB) is mainly characterised by a normal fundus appearance, loss of scotopic function, and an abnormal electroretinogram (ERG).' Though not very common, it was first described over 300 years ago as a dominant disease in the Nougaret family in France. ${ }^{2}$ Three modes of genetic transmission have since been described: a dominant form, an autosomal recessive form, ${ }^{3}$ and a sex linked recessive type. ${ }^{4}$

Two types of CSNB have been differentiated by means of the ERG. In the first type, described by Schubert and Bornschein, ${ }^{5}$ the dark-adapted response is characterised by a normal or slightly subnormal a wave, while there is no (or perhaps a minimal) scotopic b wave above baseline. This 'negative type' of ERG or type 1 ERG, is the most common type of ERG in CSNB. In the type described by Riggs ${ }^{6}$ the $a$ and $b$ waves are proportionally more reduced, and the amplitudes may vary substantially (type 2 ERG). In some cases only reduced

Correspondence to Dr K Narfström, Department of Ophthalmology, University of Linköping, S-581 85 Linköping, Sweden. photopic responses could be recorded from the darkadapted retina. There seems to be no correlation between these two ERG types and the mode of inheritance of CSNB. ${ }^{17-10}$ Recently, the SchubertBornschein type of CSNB has been further subdivided, mainly on the basis of ERG findings and psychophysical testing, into the complete type, which competely lacks rod function, and the incomplete type with some remaining rod function. ${ }^{7}$ Furthermore, in all forms of CSNB the implicit times for scotopic and photopic b waves were found to be almost the same, ${ }^{\prime}$ whereas in normal persons the implicit time of the scotopic $b$ wave is at least twice as long as that of the photopic $b$ wave.

Although the cause of CSNB is still not clear, the results of ERG and fundus reflectometric studies have contributed to our understanding of the disease. Carr and associates showed that both the concentration and regeneration of rhodopsin were normal in two cases of CSNB affected human retinae. ${ }^{12}$ One of the cases showed a 'negative' ERG, and in the other only a minimal photopic response could be elicited. It seems that the first case represents a defective transmission from the rods to the inner retina and 
that the second case involves a failure in the transduction process at some point between the initial event and the change in plasma membrane potential. ${ }^{12-14}$ The few CSNB affected eyes that have been examined histologically have not shown any morphological alterations by either light or electron microscopy. ${ }^{15} 16$ Female carriers of X-linked recessive CSNB have shown reduced oscillatory potentials. ${ }^{17}$

The pathophysiology of specific retinal disease processes in man may be elucidated by study of animal models with similar defects. A form of night blindness with similarities to the SchubertBornschein type of CSNB was reported in the Appaloosa horse. ${ }^{18}$ In this animal the trait was recessively inherited and there was behavioural evidence that the animals were night-blind. Electrophysiologically only the a wave of the ERG was recordable. Histological studies of one nyctalopic horse showed a normal retina. Transmission densitometry of an isolated retina revealed an ample supply of rhodopsin. ${ }^{14}$

In the dog recent reports of sporadic cases of nightblind Briards have been obtained, mainly from France (Lescure F, personal communication, 1987) as well as from the USA (Riis RC, Aguirre GD: The Briard problem. Unpublished: for abstract see Transactions of the Fourteenth Annual Scientific Program of the College of Veterinary Ophthalmologists, Chicago, 1983). In Sweden such a defect has also been observed and further studied in a complete litter of Briard dogs and in their parents. This paper describes some of the clinical characteristics of the disease in these dogs and compares the results with the findings in cases of CSNB in man.

\section{Subjects and methods}

DOGS

A litter of nine 10-month-old Briard dogs and their parents were studied at the Faculty of Veterinary Medicine, Swedish University of Agricultural Sciences, Uppsala. Apart from apparent night blindness in some of the dogs the breeder claimed that her dogs had been healthy since birth. The affected dogs seemed to require rather bright light to see properly. The visual problems appeared to have been stationary from birth. A general clinical examination of the dogs did not reveal any signs of disease except for visual disturbances. The ophthalmic examination included examination of the direct and indirect pupillary light reflexes, an obstacle course test under dim and bright illumination, indirect ophthalmoscopy, and slit-lamp examination after the induction of mydriasis. Electroretinography (ERG) was performed finally in eight of the dogs.

To record the ERGs the animals were anaesthetised with intravenous sodium thiopentone, intubated, and maintained in surgical anaesthesia with halothane. The pupils were fully dilated by topical application of $0.5 \%$ atrophine and $10 \%$ phenylephrine hydrochloride. A corneal contact lens electrode with a diffusing surface to provide even

Table 1 Clinical findings in 11 Briard dogs examined: five cases of nyctalopia

\begin{tabular}{|c|c|c|c|c|c|c|c|c|c|c|}
\hline & \multicolumn{10}{|c|}{ Number/age/sex } \\
\hline & $\begin{array}{l}I / 10 / F \\
m o\end{array}$ & $\begin{array}{l}2 / 10 / M \\
\text { mo }\end{array}$ & $\begin{array}{l}3 / 10 / F \\
m o\end{array}$ & $\begin{array}{l}4 / 10 / M \\
\text { mo }\end{array}$ & $\begin{array}{l}5 / 10 / F \\
\text { mo }\end{array}$ & $\begin{array}{l}6 / 10 / F \\
m o\end{array}$ & $\begin{array}{l}7 / 10 / M \\
m o\end{array}$ & $\begin{array}{l}8 / 10 / F \\
m o\end{array}$ & $\begin{array}{l}9 / 10 / \mathrm{M} \\
\text { mo }\end{array}$ & $\begin{array}{l}10 / 7 \cdot 5 / F \\
y r \quad y r\end{array}$ \\
\hline $\begin{array}{l}\text { Pupillary light } \\
\text { reflexes } \\
\text { Obstacle course } \\
\text { test: }\end{array}$ & Normal & Normal & Normal & Normal & Normal & Normal & Normal & Normal & Normal & Normal Normal \\
\hline $\begin{array}{l}\text { dim light } \\
\text { bright light }\end{array}$ & $\begin{array}{l}\text { Abnormal } \\
\text { Normal }\end{array}$ & $\begin{array}{l}\text { Abnormal } \\
\text { Normal }\end{array}$ & $\begin{array}{l}\text { Abnormal } \\
\text { Normal }\end{array}$ & $\begin{array}{l}\text { Abnormal } \\
\text { Slightly } \\
\text { abnormal }\end{array}$ & $\begin{array}{l}\text { Abnormal } \\
\text { Normal }\end{array}$ & $\begin{array}{l}\text { Normal } \\
\text { Normal }\end{array}$ & $\begin{array}{l}\text { Normal } \\
\text { Normal }\end{array}$ & $\begin{array}{l}\text { Normal } \\
\text { Normal }\end{array}$ & $\begin{array}{l}\text { Normal } \\
\text { Normal }\end{array}$ & $\begin{array}{l}\text { Normal Normal } \\
\text { Normal Normal }\end{array}$ \\
\hline $\begin{array}{l}\text { Ocular structures } \\
\text { (external } \\
\text { structure } \\
\text { and anterior } \\
\text { segment) }\end{array}$ & Normal & Normal & Normal & Normal & Normal & Normal & Normal & Normal & Normal & Normal Normal \\
\hline $\begin{array}{l}\text { Fundus } \\
\text { Dark adaptation }\end{array}$ & Normal & Normal & Normal & Normal & Normal & Normal & Normal & Normal & Normal & Normal Normal \\
\hline $\begin{array}{l}\text { during ERG } \\
\text { Dark-adapted } \\
\text { ERG }\end{array}$ & $\begin{array}{l}\text { Abnormal } \\
\text { Barely } \\
\text { recordable } \\
\text { a and b } \\
\text { waves }\end{array}$ & $\begin{array}{l}\text { Abnormal } \\
\text { Barely } \\
\text { recordable } \\
\text { a and b } \\
\text { waves }\end{array}$ & $\begin{array}{l}\text { Not done } \\
\text { Not done }\end{array}$ & $\begin{array}{l}\text { Abnormal } \\
\text { Barely } \\
\quad \text { recordable } \\
\text { a and b } \\
\text { waves }\end{array}$ & $\begin{array}{l}\text { Abnormal } \\
\text { Barely } \\
\quad \text { recordable } \\
\text { a and b } \\
\text { waves }\end{array}$ & $\begin{array}{l}\text { Normal } \\
\text { Normal }\end{array}$ & $\begin{array}{l}\text { Normal } \\
\text { Normal }\end{array}$ & $\begin{array}{l}\text { Not done } \\
\text { Not done }\end{array}$ & $\begin{array}{l}\text { Not done } \\
\text { Not done }\end{array}$ & $\begin{array}{l}\text { Normal Normal } \\
\text { Normal Normal }\end{array}$ \\
\hline $\begin{array}{l}30 \mathrm{~Hz} \text { flicker } \\
\text { ERG }\end{array}$ & Subnormal & Subnormal & Not done & Subnormal & Subnormal & Normal & Normal & Not done & Not done & Normal Normal \\
\hline
\end{tabular}


illumination of the retina was used. A reference needle was placed subcutaneously on the side of the nose near the tested eye and the dog electrically earthed through a needle at the occiput. A Tektronix amplifier (TM504) followed by a 0.3 to $1 \mathrm{kHz}$ bandpass filter, a dual trace amplifier $(5 \mathrm{~A} 18 \mathrm{~N})$, and a dual beam storage oscilloscope (5113) were used. Tracings on the oscilloscope were photographed with a Polaroid camera.

The light stimulus was provided by a $250 \mathrm{~W}$ halogen lamp and regulated by an electronic shutter (Uniblitz). Both a stimulating and a background light path were used and led to the eye via fibre optics ending $5 \mathrm{~mm}$ in front of the eye on the visual axis. Neutral density filters attenuated the $20 \mathrm{~ms}$ light stimulus in a 5 log-unit intensity range with 31000 lux as the maximum light used.

The animals were dark-adapted for 30 minutes, during which time the dark adaptation was studied by stimulating the eye every 5 minutes with white light (31000 lux). To study the sensitivity of the rod system a $20 \mu \mathrm{V}$ criterion response to white light was used for threshold determination, after a total dark adaptation time for 45 minutes. From a starting point of -5 log relative units the light intensity was increased in steps of $0.5 \mathrm{log}$ units up to full intensity. To study the cone system the eye was light-adapted (50 lux) for 10 minutes and the responses to $30 \mathrm{~Hz}$ flicker with maximum luminance were studied. The a wave was measured from the baseline and the $b$ wave from the trough of the a wave.

To compare directly the results from human ERG recordings one clinically affected litter mate and a normal 1-year-old beagle were studied under general anaesthesia (halothane) at the Department of Ophthalmology, University of Linköping, with a setup similar to the one described below for clinical work on patients.

\section{PATIENTS}

Four patients between the ages of 6 and 12 years, with a history of nyctalopia, were examined and their condition diagnosed as CSNB at the Department of Ophthalmology, University Hospital of Linköping, Sweden. Clinical testing included tests of visual acuity, fundus examination, Goldmann perimetry, and tests of colour vision (Ishihara and Dvorine pseudoisochromatic plates) and dark adaptometry (Goldmann-Weekers).

The ERG recordings were performed under topical anaesthesia in case 4 ; the other three children required general (halothane) anaesthesia. The pupils were dilated maximally and a contact lens with a silver-silver chloride electrode was used. The reference electrode was attached to the forehead. The signals passed via the electrodes to a DC amplifier and were then processed in a HewlettPackard computer system (HP 9826). Stimulus light, produced by a $150 \mathrm{~W}$ halogen lamp (Osram), passed heat absorbing and neutral density filters (Balzer) and an electromagnetic shutter (Uniblitz), and was then led by fibre optics to a tennis ball sized hemisphere, thus creating a single eye ganzfeld stimulus. The flash duration was $40 \mathrm{~ms}$. The maximum intensity of the system, zero log unit intensity, was $18000 \mathrm{~cd} / \mathrm{m}^{2}$, measured at the corneal surface. After 30 minutes of dark adaptation the eyes were exposed to light stimuli at an intensity level of $-6,-4,-3$, -2 , and $-1 \log$ relative units. Four responses at each level were averaged. Photopic flicker ERG was recorded with a $30 \mathrm{~Hz},-2 \log$ unit, stimulus and 20 responses were averaged. For electrooculography (EOG) silver-silver chloride ECG electrodes were affixed near the nasal and temporal canthi of each eye. The patients alternately fixated two LEDs positioned in a sphere, separated horizontally by an angle of $60^{\circ}$. Recordings were made at 1-minute intervals during a 12-minute dark period, followed by a 12-minute light adaptation period. The results were printed out by the HP computer system. The Arden ratio was estimated.

\section{Results}

DOGS

Table 1 summarises the findings in the 11 Briard dogs studied. Pupillary light reflexes were normal in all dogs examined. Behavioural testing of visual function clearly differentiated affected animals from normal animals. In five of the nine litter-mates visual problems were observed in the dimly lit room; affected dogs tried to find their way round an obstacle course mainly by nose and frequently colliding with objects in their way. In two of the five cases the dogs were reluctant even to move around. When bright light was turned on none of them showed any major visual problems. Four of the affected dogs looked up and found their way around by using their eyes in a normal way, while one of them still moved in a somewhat hesitant manner. An examination of the eyes, including ophthalmoscopy and biomicroscopy, failed to show any abnormalities in any of the animals examined (Fig. 1).

Fig. 2a shows the ERG of a normal Briard dog. The ERGs of the affected Briards differed markedly from those of normal dogs. It was found that the three litter mates in which ERG recordings were performed at the Faculty of Veterinary Medicine and which had showed visual disabilities in the obstacle course test also had abnormal ERGs. There was no response at all when the stimulus light was attenuated, which means that there was no response at 


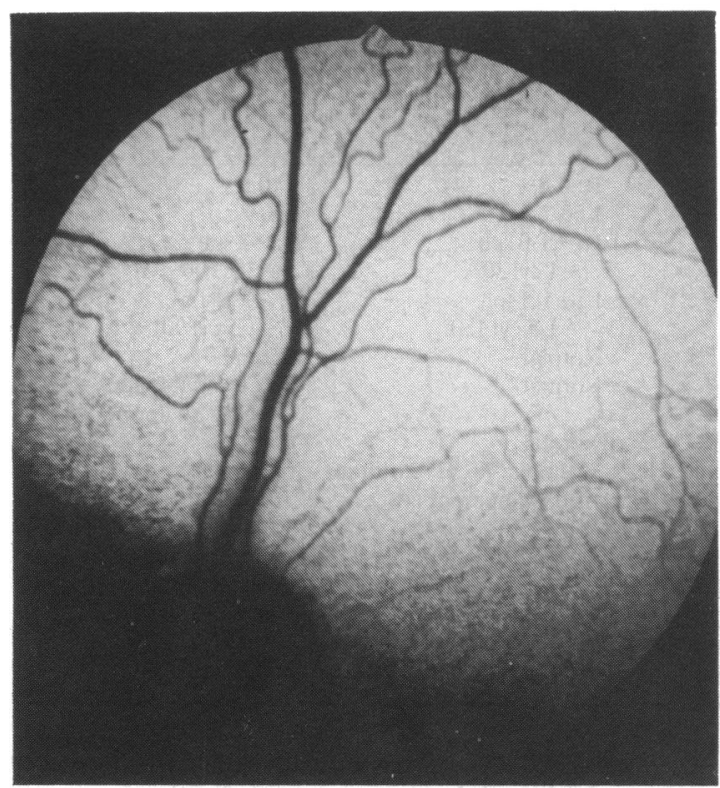

Fig. 1 The normal fundus appearance of a 10-month-old nyctalopic Briard dog (case 1).

scotopic levels. With the full light intensity, a $20 \mu \mathrm{V}$ criterion response was barely obtained (Fig. 2c). The full light intensity is clearly within the photopic range, and thus the only response obtained seems to be a reduced cone response. Photopic flicker responses from the affected animals were recordable (Fig. 2d), though subnormal when compared with the unaffected Briard dogs (Fig. 2b). This was further demonstrated at the University Hospital of Linköping, by means of the averaging technique, for one of the affected Briard dogs and a control (Fig. 3).

It is not possible to determine with certainty the genetic transmission of the defect when studying only one litter of affected dogs. The fact that both parents were unaffected, however, precludes a dominant inheritance of the defect. Both males and females were affected in the litter, which seems to rule out a sex linked inheritance. Thus the disease appears to be inherited in an autosomal recessive manner. We were surprised to learn from the study of pedigrees of the litter in Sweden and of affected Briards in the USA (Aguirre G, personal communication, 1988) that affected dogs from the two countries had common ancestors. As to how stationary these symptoms were, one of the nyctalopic dogs was donated for study and followed up for 1.5 years without any noticeable change in visual problems.

PATIENTS

Table 2 summarises the findings in patients with

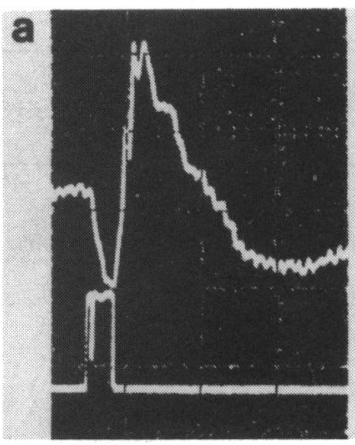

b
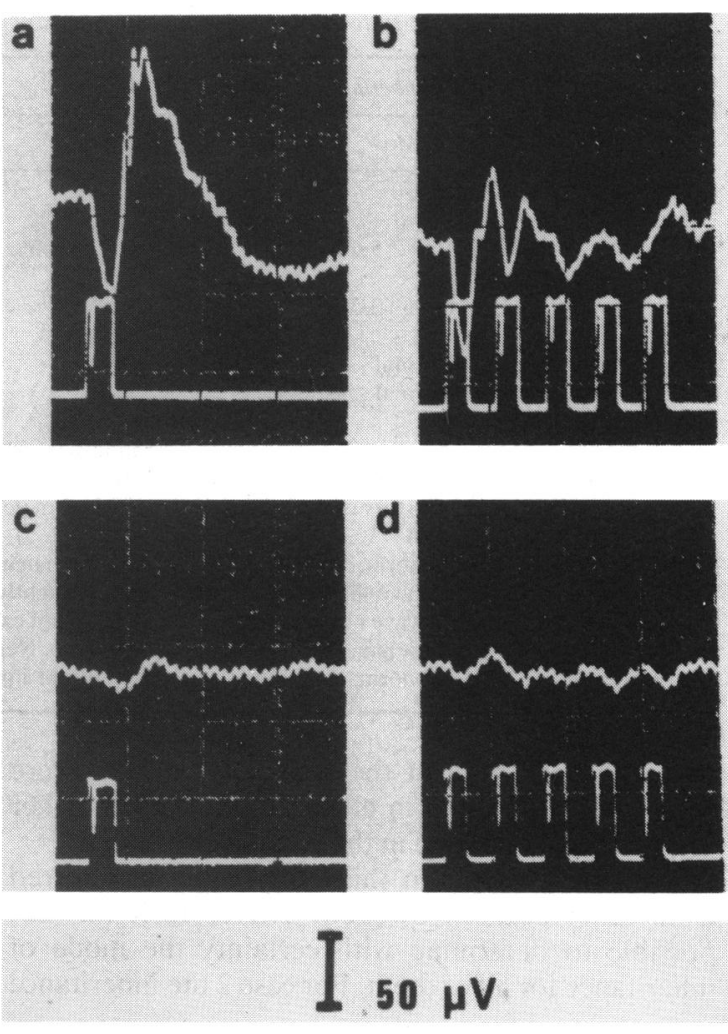

Fig. 2 (a) The normal dark-adapted ERG and (b) $30 \mathrm{~Hz}$ flicker response from an unaffected litter mate (case 7). (c) $A$ dark-adapted, low-amplitude ERG and (d) subnormal 30 $\mathrm{Hz}$ flicker response from a nyctalopic dog (case 1). Dark adaptation time for (a) and (c) 45 minutes, 20 ms of white light stimulus (31000 lux) is indicated below recordings.

CSNB. The visual fields were normal in all of them, as was the fundus appearance (Fig. 4). Colour vision was normal in two patients, slightly abnormal in one, and abnormal in one, though in the last case (case 1) the abnormality may have been due to unsatisfactory co-operation. A dark adaptation curve was not obtained in the two youngest patients, but there was a history of problems with night vision in both. In the other two patients a monophasic dark adaptation curve was recorded, in which only the cone branch was observed. A reduced light peak was recorded in the EOG in three out of the four cases.

In all four cases the dark-adapted ERG was abnormal (Fig. 5). In two cases the a wave had a normal amplitude, but it was slightly reduced in the other two. The b wave, on the other hand, did not exceed the baseline in any of the cases. Thus 'negative type' ERGs were found in all patients. In two of them a negativity following the $b$ wave was also found. Cone responses $(30 \mathrm{~Hz}$ flicker) were 
Table 2 Clinical findings in four cases of human CSNB

\begin{tabular}{|c|c|c|c|c|}
\hline & \multicolumn{4}{|l|}{ Numberlage/sex } \\
\hline & $1 / 6 / M y r$ & $2 / 6 / F y r$ & $3 / 11 / M y r$ & $4 / 12 / M y r$ \\
\hline \multirow[t]{2}{*}{ Corrected visual acuity } & $\mathrm{R}: 1 \cdot 0$ & R: $0 \cdot 4$ & $\mathrm{R}: 0 \cdot 8$ & R: $0 \cdot 6$ \\
\hline & $\mathrm{L}: 1 \cdot 0$ & L: $0 \cdot 4$ & L: 0.7 & L: $0 \cdot 7$ \\
\hline \multirow[t]{2}{*}{ Refraction } & $\mathrm{R}:+2 \cdot 5 \mathrm{sph}$ & $\mathrm{R}:+3 \cdot 5 \mathrm{sph}$ & $\begin{array}{r}\mathrm{R}:+1.0 \mathrm{sph} \\
-1 \mathrm{cyl} 30^{\circ}\end{array}$ & $\begin{array}{l}\mathrm{R}:-2 \mathrm{sph} \\
\quad-3 \mathrm{cyl} 90^{\circ}\end{array}$ \\
\hline & $\mathrm{L}: 06+2 \cdot 5$ & $\mathrm{~L}:+3 \cdot 5$ & $\begin{aligned} \mathrm{L}: & +1.5 \mathrm{sph} \\
& -1.5 \mathrm{cyl} 150^{\circ}\end{aligned}$ & $\begin{aligned} \mathrm{L}: & -3.5 \mathrm{sph} \\
& -1.5 \mathrm{cyl} 90^{\circ}\end{aligned}$ \\
\hline Visual fields & Normal & Normal & Normal & Normal \\
\hline Fundus & Normal & Normal & Normal & $\begin{array}{l}\text { Inferonasal fundus ectasia, } \\
\text { otherwise normal }\end{array}$ \\
\hline Colour vision & Abnormal & Mildly abnormal & Normal & Normal \\
\hline Dark adaptation & $\begin{array}{l}\text { DA curve not obtained } \\
\text { (history of decreased } \\
\text { DA) }\end{array}$ & $\begin{array}{l}\text { DA curve not obtained } \\
\text { (history of decreased } \\
\text { DA) }\end{array}$ & $\begin{array}{l}\text { Monophasic curve without } \\
\text { rod adaptation }\end{array}$ & $\begin{array}{l}\text { Monophasic curve without } \\
\text { rod adaptation }\end{array}$ \\
\hline EOG & Abnormal light peak & Abnormal light peak & Abnormal light peak & Normal \\
\hline Dark-adapted ERG & $\begin{array}{l}\text { a Wave slightly subnormal, } \\
\text { b wave not exceeding } \\
\text { baseline. 'Negative type' }\end{array}$ & $\begin{array}{l}\text { a Wave slightly subnormal, } \\
\text { b wave not exceeding } \\
\text { baseline. 'Negative type' }\end{array}$ & $\begin{array}{l}\text { a Wave normal, b wave not } \\
\text { exceeding baseline. } \\
\text { 'Negative type' }\end{array}$ & $\begin{array}{l}\text { a Wave normal, b wave not } \\
\text { exceeding baseline. } \\
\text { 'Negative type' }\end{array}$ \\
\hline $30 \mathrm{~Hz}$ flicker ERG & Subnormal amplitude & Subnormal amplitude & Non-recordable & Subnormal amplitude \\
\hline
\end{tabular}

recordable in three of the four patients, but were somewhat subnormal in all three. No $30 \mathrm{~Hz}$ flicker response was obtained in the 11-year-old patient.

The four patients in this study were all referred from other parts of Sweden. Therefore it was not possible to determine with certainty the mode of inheritance for all of them. For case 2 the inheritance

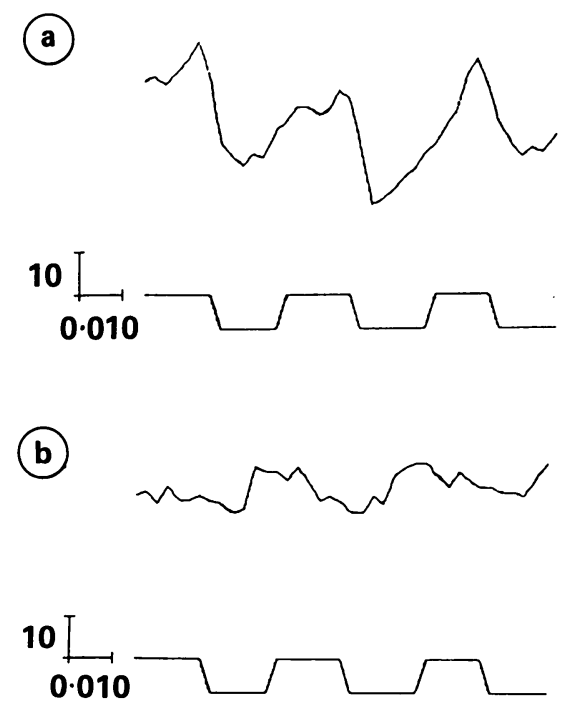

Fig. 3 The results from $30 \mathrm{~Hz}$ flicker recordings in which 20 responses were averaged. (a) The normal flicker response from a control dog. (b) The subnormal response from a nyctalopic Briard dog (case 4). Amplitude and time calibrations $10 \mu \mathrm{V}$ and $10 \mathrm{~ms}$, respectively. Stimulus intensity $-0 \cdot 5 \log$ relative unit (attenuation from a full intensity of $\left.18000 \mathrm{~cd} / \mathrm{m}^{2}\right)$. was autosomal recessive and for case $4 \mathrm{X}$-linked. For cases 1 and 3 the inheritance was probably autosomal recessive.

\section{Discussion}

The patients with CSNB and the nyctalopic Briard dogs were similar in many respects. Firstly, the problems were congenital in nature. Affected dogs had shown strange behaviour and appeared unwilling to move around in new surroundings in dim lighting, at least after they were sold at the age of 7 weeks. The patients had always had visual difficulties, especially at night.

The stationary nature of the defect in the human disease, as well as its hereditary characteristics, have been well documented. ${ }^{1-4}$ Since the four patients

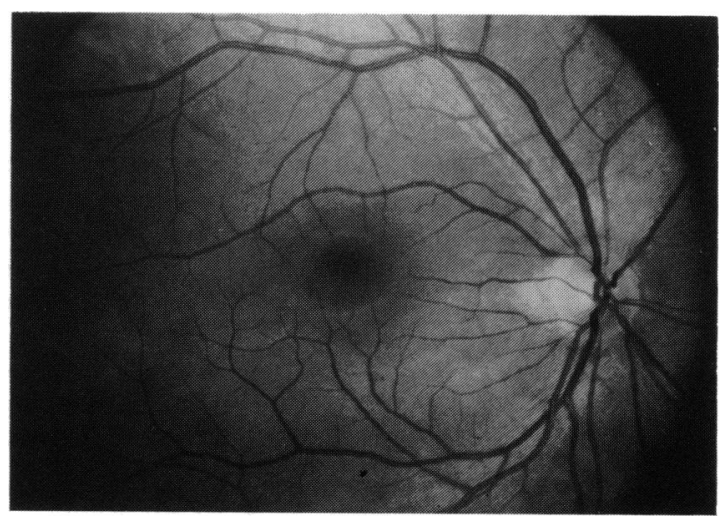

Fig. 4 Normal fundus appearance in the 11-year-old male (case 4). 


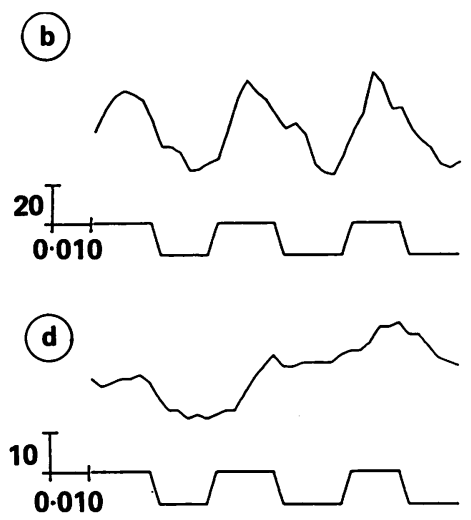

Fig. 5 (a) The normal human dark-adapted ERG, and (b) $30 \mathrm{~Hz}$ flicker response. (c) $A$ 'negative type' dark-adapted ERG (subnormal a wave and a lowamplitude $b$ wave), and (d) subnormal $30 \mathrm{~Hz}$ flicker response from a CSNB affected patient (no. 1). Amplitude and time calibrations in $\mu V$ and seconds. Stimulus intensity (a) and (c) $-1 \log$ relative unit; (b) and (d) -2 log relative units.

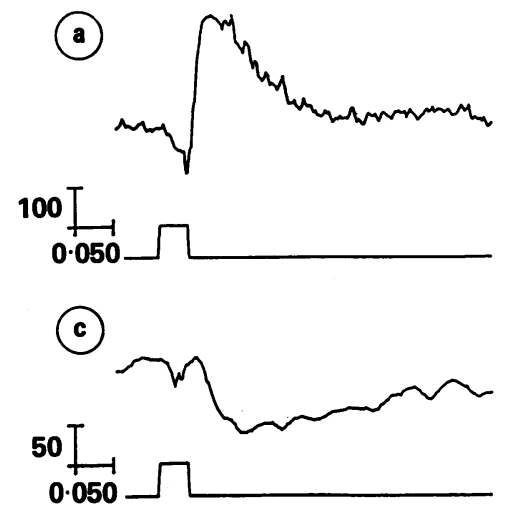


3 Gassler VJ. Über eine bis jetzt nicht bekannte recessive Verknüpfung von hochgradiger Myopie mit angeborener Hemeralopie. Thesis. Zürich: Art Orell Füssli, 1925.

4 Donders FC. Topeur de la rétine. Ann Oculist (Paris) 1855; 34: 270-3.

5 Schubert G, Bornschein H. Beiträge zur Analyse des menschlichen Elektroretinogramms. Ophthalmologica 1952; 123: $396-411$.

6 Riggs LA. Electroretinography in cases of night blindness. Am J Ophthalmol 1954; 38 (suppl): 70-8.

7 Miyake Y, Yagasaki K, Horiguchi M, Kawase Y, Kanda T. Congenital stationary night blindness with negative electroretinogram. A new classification. Arch Ophthalmol 1986; 104: 1013-20.

8 Auerbach E, Godel V, Rowe H. An electrophysiological and psychophysical study of two forms of congenital night blindness. Invest Ophthalmol Vis Sci 1969; 8: 332-45.

9 Carr RE, Siegel IM. Visual electrodiagnostic testing. Baltimore and London: Williams and Wilkins, 1982.

10 Bloome MA, Garcia CA. Manual of retinal and choroidal dystrophies. New York: Appleton-Century-Crofts, 1982.

11 Newsome DA. Retinitis pigmentosa, Usher's syndrome, and other pigmentary retinopathies. In: Newsome DA, ed. Retinal dystrophies and degenerations. New York: Raven Press, 1988: 161-94.

12 Carr RE, Ripps H, Siegel IM, Weale RA. Rhodopsin and the electrical activity of the retina in congenital night blindness. Invest Ophthalmol Vis Sci 1966: 5: 497-5()7.

13 Carr RE. Congenital stationary night blindness. Trans Am Ophthalmol Soc 1974: 72: 448-87.

14 Ripps $H$. Night blindness revisited: from man to molecules. Proctor lecture. Invest Ophthalmol Vis Sci 1982; 23: 588-609.

15 Babel J. Constatations histologiques dans lamaurose enfantile de Leber et dans diverses formes d'hémeralopie. Ophthalmologica 1963; 145: 399-402.

16 Watanabe I, Taniguchi Y, Morioka K, Kato M. Congenital stationary night blindness with myopia: a clinico-pathologic study. Doc Ophthalmol 1986; 63: 55-62.

17 Miyake Y, Kawase Y. Reduced amplitude of oscillatory potentials in female carriers of $\mathrm{X}$-linked recessive congenita stationary night blindness. Am J Ophthalmol 1984; 98: 208-15.

18 Witzel DA, Smith EL, Wilson RD, Aguirre GD. Congenital stationary night blindness: an animal model. Invest Ophthalmol Vis Sci 1978; 17: 788-95.

19 Norren D van, Padmos P. Cone dark adaptation: the influence of halothane anesthesia. Invest Ophthalmol Vis Sci 1975: 14: 212-7.

20) Raitta C, Karhunen U, Seppäläinen M, Naukkarinen M. Changes in the electroretinogram and visual evoked potentials during general anaesthesia. Graefes Arch Clin Exp Ophthalmol 1979; 211: 139-44.

Accepted for publication 11 April 1989. 